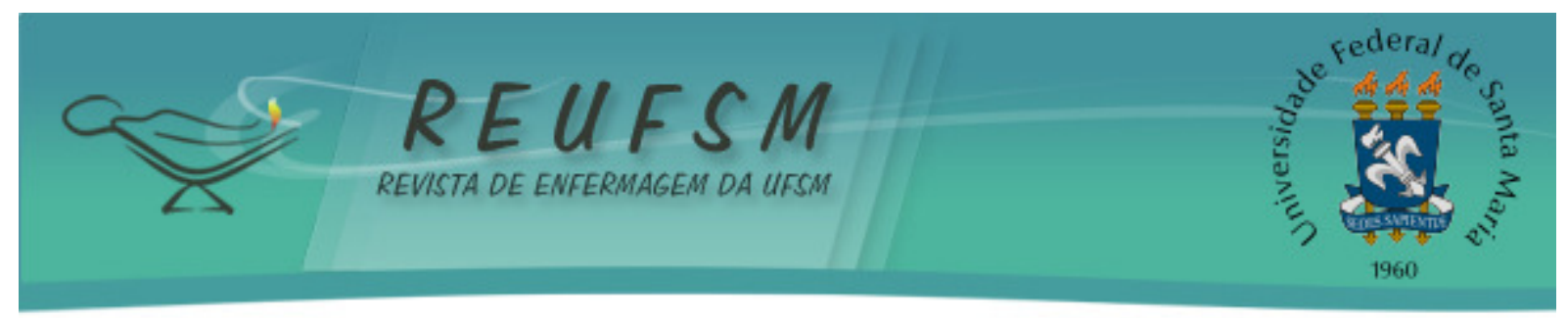

RELATO DE EXPERIÊNCIA

\title{
RODAS DE TERAPIA COMUNITÁRIA: CONSTRUINDO ESPAÇOS TERAPÊUTICOS PARA IDOSOS EM COMUNIDADES QUILOMBOLAS
}

\section{COMMUNITY CARE CONVERSATION ROUNDS: BUILDING THERAPEUTIC SPACE FOR THE ELDERLY IN QUILOMBOLAS COMMUNITIES}

\section{RUEDAS DE TERAPIA COMUNITARIA: CONSTRUYENDO ESPACIOS TERAPÉUTICOS PARA ANCIANOS EN COMUNIDADES QUILOMBOLAS}

\author{
Sanni Moraes De Oliveira ${ }^{1}$ \\ Jonas Oliveira Menezes Junior ${ }^{2}$ \\ Sergio Vital Da Silva Junior ${ }^{3}$ \\ Maria Djair Dias ${ }^{4}$ \\ Maria Das Graças Melo Fernandes 5 \\ Maria De Oliveira Ferreira Filha ${ }^{6}$
}

Doi: $10.5902 / 2179769220299$

RESUMO: Objetivo: relatar a experiência de um projeto de extensão universitária sobre rodas de Terapia Comunitária Integrativa em quilombos, que ofertou aos idosos dessa comunidade um espaço terapêutico de escuta e fala na partilha de sofrimentos e descobertas. Método: participaram 16 pessoas, com idade entre 60 e 80 anos no período de maio de 2013 a janeiro de 2014, no Conde, Paraíba. Resultados: as histórias de vida relatadas nas rodas desenvolvidas foram marcadas pelo tema da luta pela terra, acesso à moradia, saúde, educação, geração de emprego e renda. Os sofrimentos revelados foram: preocupação com doenças, medo de tornar-se inútil frente ao envelhecimento e conflitos familiares. Considerações finais: constatou-se a relevância social dessa ferramenta, uma vez que a mesma oportunizou momentos de expressão da subjetividade ligados à cultura afrodescendente.

Descritores: Grupo com ancestrais do continente africano; Enfermagem em saúde comunitária; Saúde mental.

ABSTRACT: Aim: to report the experience of a university extension project on Community Therapy Integrative Conversation Rounds in quilombos, which has offered the elderly of this community a therapeutic space for listening and speaking in sharing sufferings and discoveries. Method: 16 people, aged between 60 and 80 years-old, in the period from May 2013 to January 2014 in Conde, Paraiba, participated. Results: the life stories reported in the developed conversation rounds were marked by the theme of the struggle for land, access to housing, health, education, employment and income. The revealed sufferings were concerned with diseases; fear of becoming useless against the aging and family conflicts.

\footnotetext{
${ }^{1}$ Enfermeira, Universidade Federal da Paraíba, João Pessoa, Paraíba, Brasil. sannidsm@gmail.com

2 Psicólogo, Universidade Federal da Paraíba, João Pessoa, Paraíba, Brasil. juniormenezes07@yahoo.com.br

${ }^{3}$ Enfermeiro, Universidade Federal da Paraíba, João Pessoa, Paraíba, Brasil. sergioenfe1@gmail.com

4 Enfermeira, Doutora em Enfermagem, Universidade Federal da Paraíba, João Pessoa, Paraíba, Brasil. mariadjair@yahoo.com.br

${ }^{5}$ Enfermeira, Doutora em Enfermagem, Universidade Federal da Paraíba, João Pessoa, Paraíba, Brasil. graacafernandes@hotmail.com

${ }^{6}$ Enfermeira, Doutora em Enfermagem, Universidade Federal da Paraíba, João Pessoa, Paraíba, Brasil. marfilha@yahoo.com.br
} 


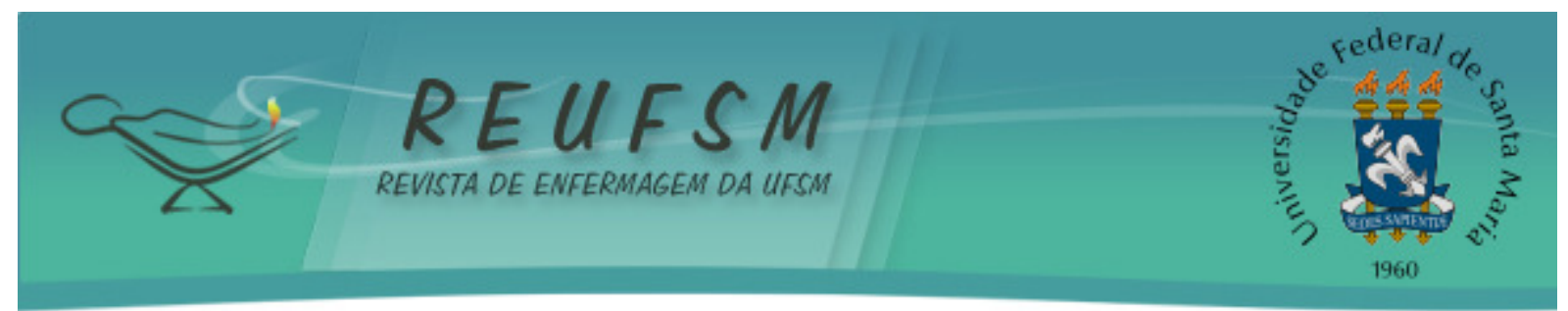

Final thoughts: it was found the social relevance of this tool, since it provided an opportunity of moments of subjective expression related to Afro-descendant culture.

Descriptors: Group with ancestors of the African continent; Community health nursing; Mental health.

RESUMEN: Objetivo: relatar la experiencia de un proyecto de extensión universitaria sobre ruedas de Terapia Comunitaria Integrativa, en quilombos, que ofreció a los ancianos de esta comunidad un espacio terapéutico de escucha y habla para el intercambio de sufrimientos y descubrimientos. Método: participaron 16 personas, con edades entre los 60 y los 80 años, en el período de mayo 2013 y enero 2014, en Conde, Paraíba. Resultados: las historias de vida narradas en las ruedas fueron señaladas por el tema de la lucha por la tierra, del acceso a la vivienda, a la salud, a la educación, al empleo y a la renta. Los sufrimientos revelados fueron: preocupación con enfermedades; miedo de ser inútil, en función de la viejez, y conflictos familiares. Consideraciones finales: se constató la relevancia social de esta herramienta, ya que proporcionó un espacio para la expresión subjetividad relacionado a la cultura afrodescendiente.

Descriptores: Grupo con los ancestros del continente africano; enfermería en salud comunitaria; Salud mental.

\section{INTRODUÇÃO}

O Brasil tem avançado gradativamente no campo das políticas sociais ao adotar um sistema de saúde universal, descentralizado, que oferta ações preventivas e curativas e garante a participação da comunidade na gestão. ${ }^{1}$

Em 1994, o Ministério da Saúde concebeu a Estratégia Saúde da Família como uma promissora proposta de reorganização das práticas assistenciais da atenção primária à saúde visando à reorientação do modelo tradicional, centrado no tratamento de doenças e na atenção especializada ofertada pela rede ambulatorial/hospitalar, para uma forma de assistência na qual seja privilegiada a integralidade da atenção ao usuário, considerando o conceito de família e os aspectos da promoção da saúde..$^{2-3}$

Com o surgimento da reforma psiquiátrica no Brasil, o modelo vigente de atenção à saúde mental, a saber, o hospitalocêntrico, que é curativo e excludente passou a ser rediscutido, ressignificando as práticas em um modelo reabilitador, de base comunitária, cujo eixo norteador das ações é o coletivo, a promoção da saúde, a prevenção do adoecimento e a inclusão social, tendo em vista os sujeitos, a família e os grupos sociais. ${ }^{4}$ No modelo comunitário, torna-se imperioso transformar os modos de cuidar do sujeito, deslocando o objeto para a existência e sofrimento do indivíduo e sua relação com a sociedade. ${ }^{5}$ 


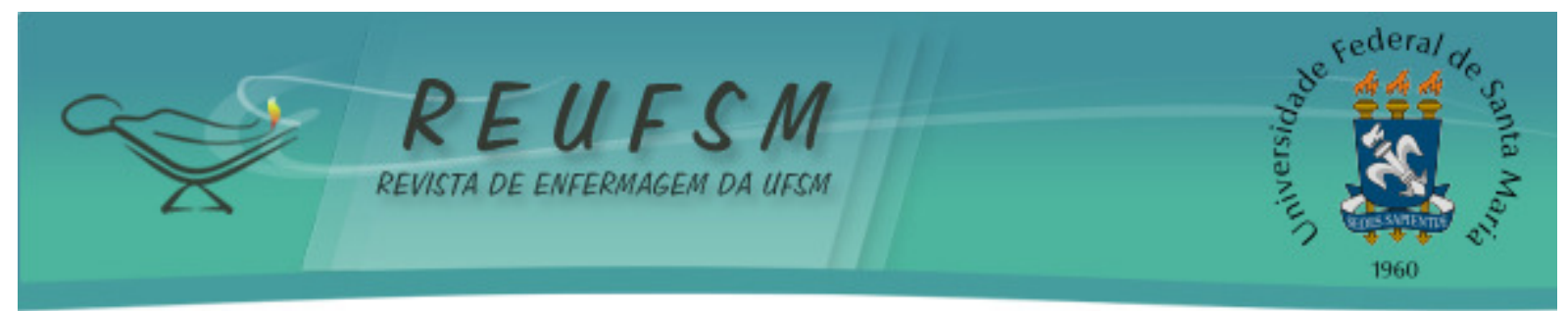

O novo olhar para saúde mental passou a levar em consideração não só o indivíduo, mas todo o contexto social onde este está inserido, assim como se constatou que as ocorrências de doenças mentais aconteciam mais do que se imaginavam e que os tratamentos disponíveis apresentavam limitações. Logo, estratégias com o enfoque no fortalecimento da saúde e na redução dos riscos passaram a ser cada vez mais valorizadas. ${ }^{6}$

A Terapia Comunitária Integrativa (TCI) foi criada em 1987, pelo médico psiquiatra, teólogo e antropólogo, professor Dr. Adalberto de Paula Barreto, do Departamento de Saúde Comunitária da Faculdade de Medicina da Universidade Federal do Ceará na comunidade de Pirambu/Fortaleza/Ceará. ${ }^{7}$

A partir de 2008, a TCI passou a compor a Atenção Básica em Saúde (ABS), por meio da Política Nacional de Práticas Integrativas e Complementares (PNPIC). No ano de 2013, a TCI foi implementada pela Política Nacional de Saúde Mental como prática avançada de cuidado. ${ }^{8}$

A TCI fomenta a participação e autonomia, pois proporciona aos integrantes, recursos no âmbito individual e coletivo utilizando-se das propriedades terapêuticas emergentes das relações interpessoais na sociedade comunitária. ${ }^{9}$

Pode-se dizer que essa abordagem se constitui numa metodologia facilitadora da autonomia, haja vista que potencializa os recursos individuais e coletivos, na medida em que se apropria das qualidades e forças existentes em potência nas relações sociais. Essa ferramenta de cuidado possui uma base teórica e conceitual fundamentada em cinco pilares: o pensamento sistêmico, a teoria da comunicação, a antropologia cultural, a pedagogia freiriana e a resiliência. ${ }^{10}$

Cada eixo teórico sustenta a formação e a prática do terapeuta que passa a conduzir as rodas de TCI como um facilitador do processo terapêutico grupal, respeitando as singularidades.

Isto posto, cumpre salientar que a TCI é exercida por profissionais de distintas categorias e a enfermagem se destaca, pelo interesse nessa ferramenta devido a sua inserção no campo da saúde coletiva e a busca por uma tecnologia de cuidado, na busca em assegurar maior acesso da população aos serviços de saúde da rede básica, mas também por priorizar a promoção da saúde e a prevenção do adoecimento psíquico. ${ }^{11}$

Enquanto dispositivo que favorece o cuidado, a TCI se consolida como uma nova tecnologia leve de cuidado em saúde mental comunitária, constituindo-se em um instrumento valioso de intervenção psicossocial na saúde coletiva. A TCI não pretende substituir outros serviços de saúde, mas complementá-los, de modo a ampliar as ações preventivas e promocionais. ${ }^{12}$ 


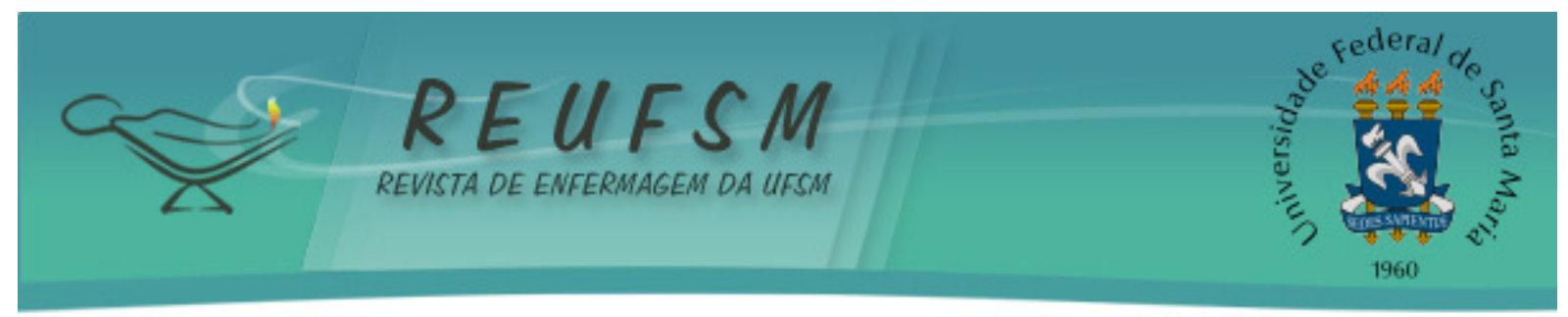

Ressalta-se que a aprovação da Política Nacional de Práticas Integrativas e Complementares em 2006 proveu subsídios para estender a prática que já acontece há mais de vinte anos em Fortaleza a outras regiões do país. Em 2008, um convênio entre o Ministério da Saúde e a Fundação Cearense de Pesquisa e Cultura foi firmado para implantar a TCI na Rede de Assistência à Saúde do Sistema Único de Saúde (SUS). O projeto visa desenvolver, nos profissionais de saúde e nas lideranças comunitárias, as competências necessárias para lidar com os sofrimentos e demandas psicossociais e promover redes de apoio social, ampliando a resolutividade da Atenção Primária em Saúde. ${ }^{13}$

A inserção da TCI no SUS advém das demandas expressas na Política Nacional de Atenção Básica, entre elas: a implementação das diretrizes da Política Nacional de Humanização por meio do acolhimento, da realização da escuta qualificada das necessidades dos usuários e do estabelecimento do vínculo. ${ }^{14-15}$ Direciona-se também aos interesses da Política Nacional de Promoção da Saúde, que tem como uma de suas diretrizes fortalecer a participação social, entendendo-a como fundamental na consecução de resultados de promoção da saúde, em especial, a equidade e o empoderamento individual e comunitário, privilegiando as práticas de saúde sensíveis à realidade do Brasil. ${ }^{13}$

As rodas de TCI são caracterizadas como um espaço de promoção de encontros, interpessoais e intercomunitários, partilhando experiências de vida e sabedoria de forma horizontal e circular, por meio do acolhimento e escuta dos participantes e de seus sofrimentos. Objetiva a valorização das histórias de vida dos integrantes, a restauração da autoestima e da confiança em si, a ampliação da percepção dos problemas e possibilidades a prevenção das consequências do estresse habitual. ${ }^{14-16}$

Destarte, a prática de efeito terapêutico da TCI, destinada à prevenção na área da saúde mental e ao atendimento de grupos heterogêneos pelo contato face-a-face, tem como base de sustentação a construção de vínculos solidários por meio de uma rede de apoio social, pela qual a comunidade busca resolver os problemas de forma coletiva. ${ }^{17}$

Desse modo, interessados em proporcionar espaços terapêuticos populares de TCI, o projeto de extensão universitária desenvolveu as atividades nas comunidades quilombolas do Gurugi e Ipiranga, localizada no município do Conde, Paraíba, junto ao Grupo de Idosos desta localidade.

Partindo deste contexto, e com a vontade de fortalecer a práxis da Enfermagem no âmbito da saúde mental comunitária, bem como para firmação da TCI efetivamente no SUS, 


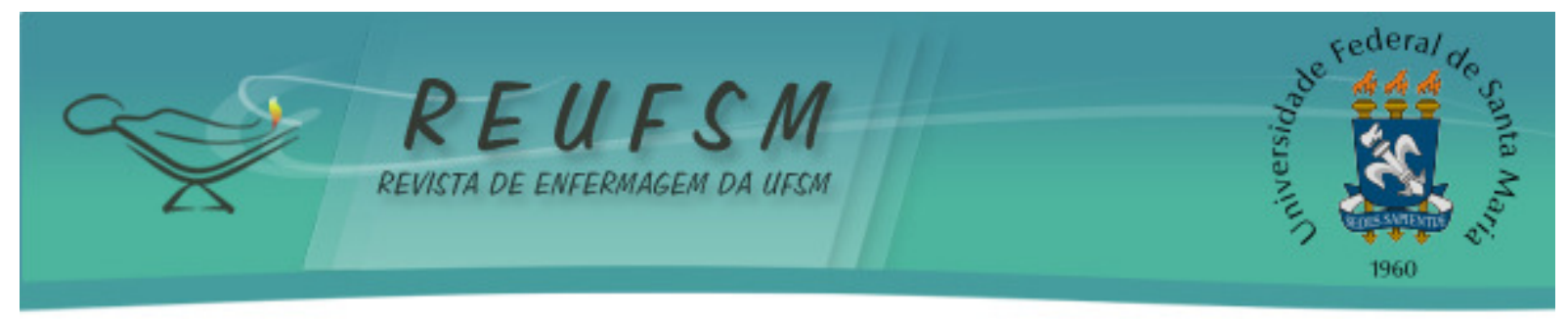

na tentativa de minimizar os transtornos mentais, em especial dessa comunidade, este estudo tem como objetivo relatar a experiência de um projeto de extensão universitária sobre rodas de Terapia Comunitária Integrativa em quilombos, que ofertou aos idosos dessa comunidade um espaço terapêutico de escuta e fala na partilha de sofrimentos e descobertas.

\section{MÉTODO}

Trata-se de um relato de experiência do projeto de extensão promovido pela Universidade Federal da Paraíba, intitulado: Rodas de Terapia Comunitária: construindo espaços terapêuticos populares nas comunidades quilombolas, no município do Conde, Paraíba, no período compreendido entre maio de 2013 a janeiro de 2014.

Os dois quilombos dessa região são ricos em cultura afro e saberes populares: Gurugi e Ipiranga possuem mais de 200 anos de existência e uma vasta história na formação do povo paraibano do Litoral Sul. Encontram-se localizado entre o Vale do Rio Gurugi e do Rio Gramame, no município do Conde. Há pelo menos quatro gerações este território é habitado por aproximadamente 250 famílias descendentes de negros escravizados, trazendo o Coco de Roda como principal manifestação cultural do seu povo e é neste contexto que o estudo foi desenvolvido. ${ }^{18}$

Ambas comunidades são marcadas por uma história de luta por direitos básicos, tais como moradia, saúde, abastecimento de água e acesso. Encontramos neste território a Associação de Moradores, construída por iniciativa de seus moradores como forma de reivindicação por melhores condições de vida. Nos discursos informais com alguns integrantes da Associação, as reivindicações são principalmente em busca da construção de cisternas, pela precariedade do abastecimento de água na região; postos de saúde e atendimento médico que contemple a peculiaridade quilombola, visto que atualmente se possui apenas uma Unidade de Saúde da Família, que não consegue dar o suporte necessário a todas as famílias; ensino de qualidade; segurança; programas de geração de emprego e renda, adequados à realidade quilombola.

O público participante da TCI foram pessoas com idade entre 60 e 80 anos, integrantes do Grupo de Idosos, que residiam nos quilombos Guruji e Ipiranga e que participavam de reuniões na Associação de Moradores.

A aproximação inicial com o público deste estudo aconteceu de forma intencional, na perspectiva de criação de vínculo para implantação das rodas de TCI, com apresentação dos 


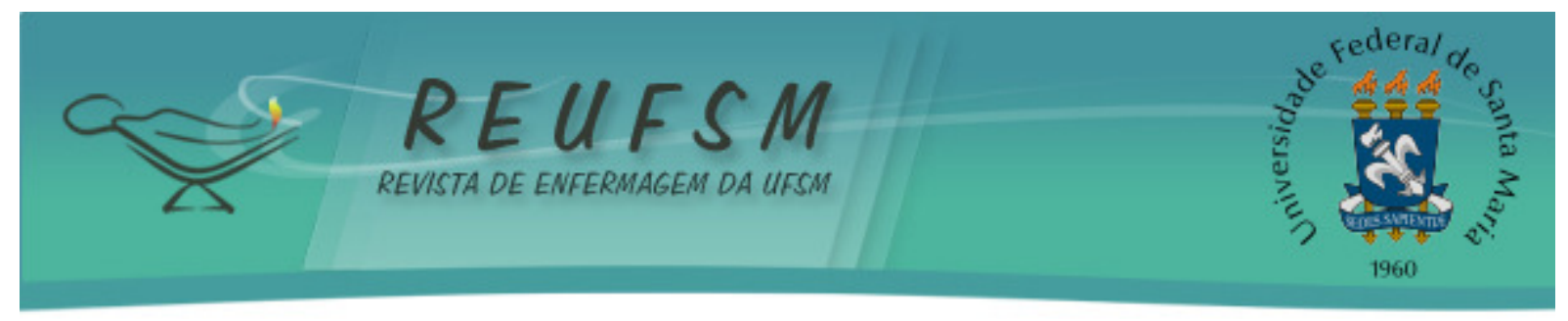

integrantes do grupo e, por conseguinte, dos propósitos do desenvolvimento da TCI e os objetivos da pesquisa.

Posteriormente, a partir do contato prévio com as articuladoras principais desta localidade, houve plena receptividade e mobilização para que a investigação se tornasse possível.

As rodas de TCI foram realizadas na Associação dos Moradores, já que alguns idosos frequentavam a associação semanalmente a fim de compartilhar e planejar as suas atividades coletivas.

Foram realizadas 10 rodas de TCI quinzenalmente, aos domingos, com duração de 2 horas cada, sem critérios de inclusão/exclusão dos participantes, tendo em média 16 idosos por encontro.

A TCI foi desenvolvida numa roda ou círculo e as pessoas sentaram-se lado a lado, de modo que permitisse a visualização dos participantes entre si, sendo conduzida pela docente terapeuta, com competência reconhecida para esta atividade e estudantes bolsistas enquanto apoio do processo, quanto aos registros audiovisuais e escritos.

Os encontros de TCI obedeceram às fases sistematizadas do método, bem como aos protocolos de cada fase. Inicia-se pelo acolhimento e, em seguida, pela escolha do tema, contextualização, problematização e encerramento. $\mathrm{O}$ acolhimento busca promover a interação social, explicitação sobre espaço de partilha de experiências, indicando momentos de fala e escuta, menção às regras (fazer silêncio, falar na primeira pessoa, não dar conselhos nem sermões). Pode-se cantar, narrar um conto breve ou uma piada que tenha a ver com o tema, celebrar aniversários, datas comemorativas, inclusive dar menção a cultura que o povo pertence e posteriormente propõe-se uma dinâmica interativa, permitindo que o grupo possa "quebrar o gelo" e se socializar de forma mais vivencial e próxima ao outro. ${ }^{16}$

Posterior ao acolhimento, procedeu-se a escolha do tema, lembrando-lhes do ditado popular: "quando a boca cala, os órgãos falam", trazendo-os a reflexão que "se puder falar com suas bocas, falem, para que o guardado não vire patologia”. Pedia-se que expressassem suas angústias de forma breve e para que não trouxessem segredos para a roda, mas os problemas cotidianos, aquilo que tira o sono (educação dos filhos, falta de emprego, aumento das contas), aquilo que traz baixa autoestima, ansiedade, insônia ou desespero. Perguntava-se então quem desejava partilhar alguma inquietação. $O$ terapeuta orientava para que a partilha fosse breve, apenas anunciada, pois em seguida seria feita uma votação para escolher o tema da roda. Após 


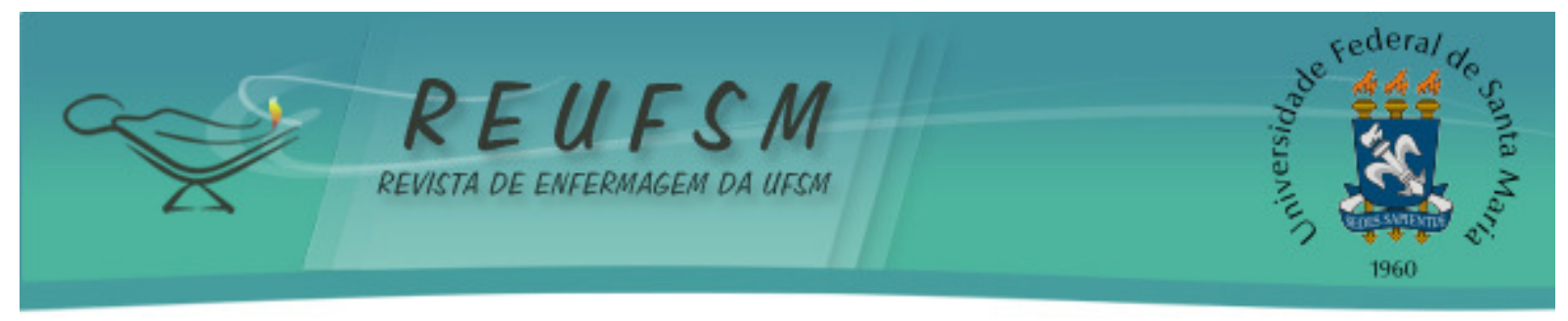

esse momento, o terapeuta tentava buscar nos participantes a ressonância com as temáticas apresentadas e em seguida colocava-as em votação. O tema mais votado pelo grupo era posto para reflexão. Este momento da escolha do assunto a ser discutido configurava-se em um ato pedagógico, pois as pessoas eram encorajadas a assumir as escolhas feitas.

Seguia-se com a contextualização, e o participante cujo tópico foi escolhido apresentava sua inquietação de forma mais detalhada, num espaço de tempo de aproximadamente 15 minutos para explanação. Nesse momento, tanto o terapeuta como os participantes do grupo dirigem-se à pessoa em questão fazendo perguntas para compreender o sofrimento dela. Após os participantes terem compreendido de modo sistêmico, qual era o contexto do problema, como ele afetava a pessoa e quais as inter-relações envolvidas, passava-se para a fase seguinte.

A problematização iniciava quando o terapeuta perguntava aos participantes: quem já havia vivenciado uma situação semelhante e como havia superado ou enfrentado esta adversidade? Por fim, seguia-se com o ritual de agregação, ocasião esta, em que os participantes valorizavam as experiências dos outros e a própria, e simbolicamente representavam a teia solidária que se formava a partir da elevação da espiritualidade, da fé e da esperança. Então, se dava o momento de fechamento, por meio da dimensão cultural, que se faz muito presente. Assim, encerrava-se a roda, num momento de confraternização com mesa de frutas da região e comidas regionais preparadas pelos próprios integrantes.

\section{RESULTADOS E DISCUSSÃO}

A proposta central do projeto foi proporcionar uma ação de promoção da saúde e prevenção do adoecimento, com a participação de rodas de TCI e analisar sua resolutividade frente aos problemas dos participantes, conferindo a eles um espaço terapêutico de escuta e de fala na partilha de sofrimentos e descobertas, privilegiando o saber e a competência construída pela experiência de vida de cada pessoa.

Na primeira visita nas comunidades do Gurugi e Ipiranga, realizaram-se visitas informais nas casas dos moradores, no intuito de divulgar as rodas de TCI e conhecer sobre o cotidiano daquele povo, no intuito de criar vínculo, conhecendo de perto as famílias em sua realidade de vida. 


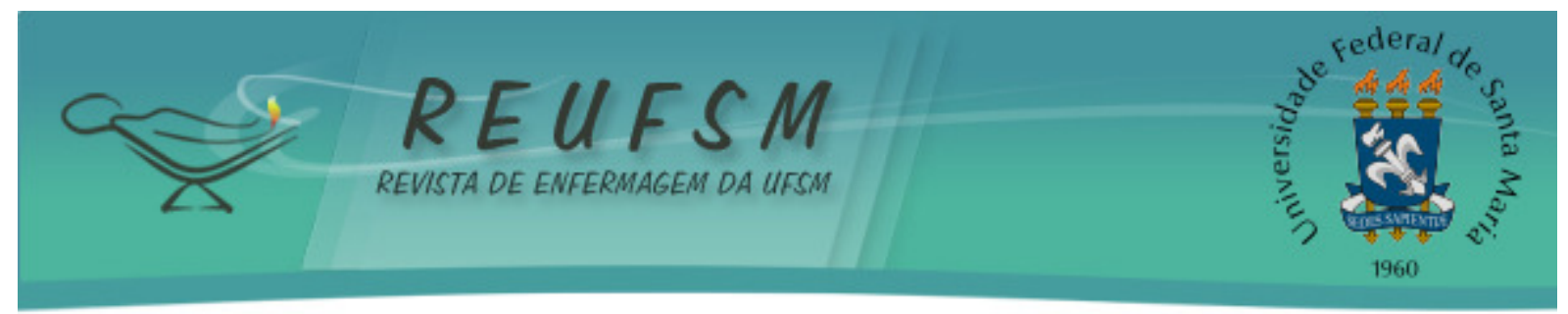

Apesar das adversidades sociais e econômicas enfrentadas, os referenciais de cultura são elos e elemento enquanto expressão da empoderamento popular, ensinando e unindo esses sujeitos históricos.

Por meio das visitas ao território onde o presente estudo aconteceu, verificou-se a alta vulnerabilidade de adoecimento no âmbito da saúde mental, tendo em vista que a população se encontrava desassistida de recursos terapêuticos que proporcionassem a oferta de escuta clínica e social, atividades de cunho comunitário que promovessem a socialização e troca de saberes, além de ações de promoção e prevenção em saúde física e mental.

As comunidades se configuram como territórios bastante enriquecidos da cultura afrodescendente, marcados pela história de luta pela terra. No entanto, a dimensão étnicoracial tornou-se na atualidade uma preocupação das políticas públicas, uma vez que as populações negras e indígenas são as que mais têm sofrido ao longo dos anos o efeito da discriminação econômica e cultural. Evidencia-se nestes grupos problemas relacionados à moradia, dificuldades de acesso a serviços de saúde e educação, evidenciando desigualdades nos perfis de adoecimento e morte. ${ }^{19-20}$

Seguindo a trajetória das atividades do projeto de extensão, juntamente com os organizadores do Grupo de Idosos, realizou-se as rodas de TCI e foi possível evidenciar uma multiplicidade de fatores que favoreciam o adoecimento físico e mental, em virtude das situações de estresse emocional às quais essas pessoas são expostas todos os dias, por muitas vezes não conseguirem acessar as políticas públicas, nem universais nem específicas, nesses territórios.

Na primeira experiência, propriamente dita, de realização das rodas de TCI, um momento que evidenciou a união do grupo e trouxe a reflexão quanto à importância do fortalecimento de vínculos, tratou-se da "Dinâmica da Teia", sendo solicitado que todos os participantes formassem um círculo, ficando um responsável por segurar a extremidade de um novelo de lã e passar aleatoriamente para qualquer integrante, apresentando-se brevemente, e referindo uma palavra representando "o que trouxe" e "o que desejaria levar" do encontro da TCI, sucessivamente passando por todos, até que se formasse uma verdadeira teia entre uns e outros. Palavras de paz, felicidade, amizade, força e resiliência foram desejadas e sentimentos de angústias e tristezas foram deixados para trás. Esta dinâmica trouxe a reflexão sobre a importância de tecer redes, ou seja, da importância da cooperação mútua para a sustentação das relações, pois se uma única pessoa soltasse uma parte sequer do novelo de lã, a teia seria desfeita. 


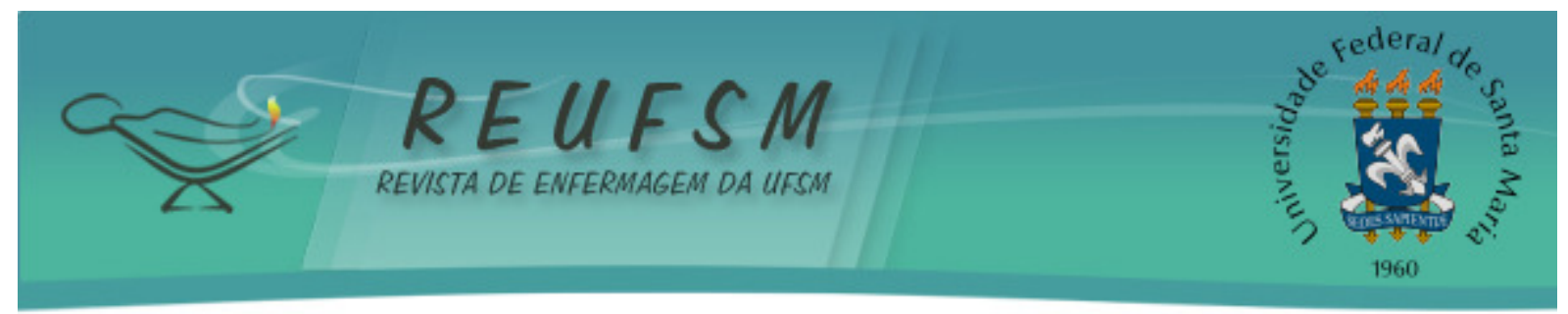

No desenvolvimento subsequente das rodas de TCI e dos resultados apreendidos, por meio das falas dos participantes e da partilha dos problemas, verificou-se que os principais sofrimentos evidenciados, estavam relacionados com a preocupação frente às doenças, principalmente inerentes ao envelhecimento.

Isto se dá ao fato de que essas pessoas em sua juventude sempre foram ativas, trabalhadoras e passaram a sentir medo de se tornarem inúteis diante dessas circunstâncias advindas do processo de envelhecer, desenvolvendo o medo de procurar assistência médica e constatarem suas doenças.

Outro agravante relacionado ao sofrimento mental na população desta investigação foram os conflitos familiares, que mostraram-se como eixos prejudiciais para a saúde mental dos integrantes.

Diante de tais ponderações, os idosos sob orientação da terapeuta selecionaram as preocupações mais relevantes naquele dado momento e ali, após a escuta do problema, passaram a construir soluções e trazer experiências de vida, ofereciam apoio, prestavam conselhos demonstrando ser solícitos uns aos outros, compartilhando vivências no intuito de ajudar aquele integrante que estava frente aquela situação conflitante. Sempre de forma dinâmica, as rodas eram regadas a músicas inspiradoras de otimismo e fé.

Pode-se dizer que as rodas de TCI atuam na saúde humana numa perspectiva integrativa, na qual a compreensão da cultura, história de vida, contextos sociais, políticos, familiares e comunitários são valorizados e os múltiplos discursos mantinham relações enraizadas com a história e cultura do povo.

A presente investigação mostra que a TCI se consolida como uma estratégia de promoção à saúde mental e a prevenção de doenças, à medida que pessoas se reúnem a fim de construir um grupo de caráter terapêutico cujas abordagens estão relacionadas ao enfrentamento dos impasses do dia-a-dia. A partir da escolha de temas passíveis de preocupação no cotidiano das pessoas presentes, estas deram depoimentos e lições de sabedoria de vida, compartilharam experiências que foram desde saberes populares até noções referentes ao exercício da cidadania; trataram de temas sobre o convívio familiar, tratamentos alternativos e até receitas caseiras. E sempre que podiam, improvisavam com músicas, momentos de oração, além das rodas de Coco, elemento de forte elo cultural dessas comunidades.

Dentre as mudanças nos discursos após a prática das rodas de TCI, estão: adesão da comunidade em participar das rodas; o interesse da comunidade em revitalizar a associação 


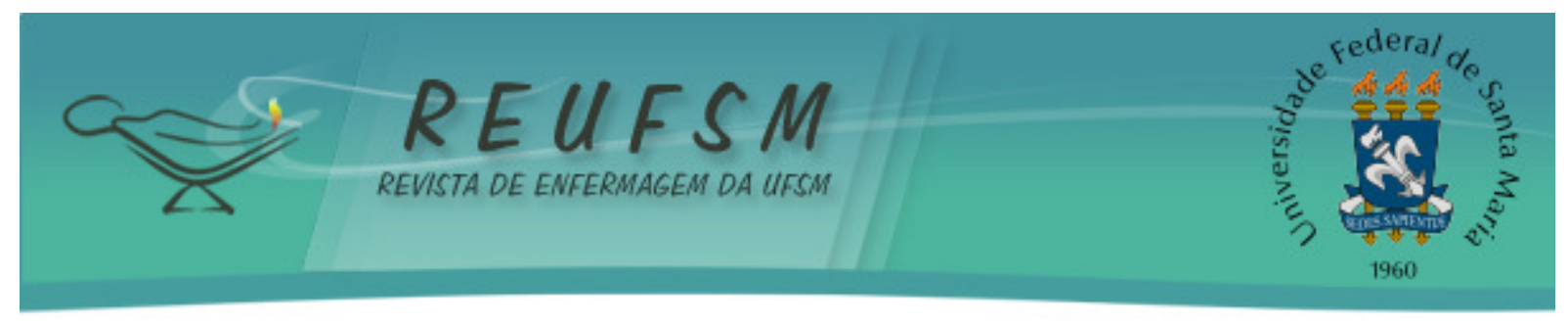

comunitária e reestruturar o Grupo de Idosos; o fortalecimento do grupo e o entusiasmo para realizar uma viagem coletiva; a maior atenção à saúde; o aumento dos relatos de procura por serviços de saúde; o incentivo da cultura por meio de participação no Coco de Roda.

Dentre as contribuições da TCI destacam-se o alívio do sofrimento, a valorização e fortalecimento pessoal e formação de vínculos solidários, reforçando os vínculos e evitando a desintegração social e emocional e estes, por sua vez, contribuem para o resgate da autoestima e autoconfiança, do sentimento de pertença, do processo de resiliência e empoderamento, bem como diminuição a sobrecarga emocional dos participantes e a conscientização do cuidado de si mesmo e do outro. ${ }^{21-22}$

É diante da troca de experiências que se permite a construção de conhecimento coletivo, na medida em que o grupo participante tem o que dizer, quem ouvir e, ao final, levar consigo novos ideais, pela elaboração e um novo ressignificado de suas experiências bem como modelos explicativos para as dores de sua vida. Desta forma, a TCI vai tecendo redes de apoio, integrando novos conhecimentos, articulado setores da sociedade, envolvendo pessoas e, acima de tudo, dimensionando suas ações para o fortalecimento da integralidade do sujeito por meio de questionamentos em todos os níveis: biológico, psicológico, social e político. ${ }^{23-25}$

\section{CONCLUSÃO}

Percebeu-se a importância e a viabilidade da TCI como um dispositivo privilegiado de acolhimento e compartilhamento de experiências, destacando o seu efeito terapêutico. Desenvolver a TCI junto ao Grupo de Idosos mostrou-se como mais uma possibilidade de intervenção de promoção de saúde e prevenção do adoecimento com este público. A confirmação da pertinência desta metodologia junto ao referido grupo foi denotada pelo respaldo dos integrantes ao avaliarem positivamente as reuniões realizadas nesta modalidade.

A prática da TCI revela-se como uma forma de cuidado, que não demanda recursos extraordinários para sua execução, mas que, no entanto, representa resolutividade e relevância social, uma vez que oportunizou a transformação de realidades, suscitando a reflexão das experiências e dos processos de sofrimento de cada indivíduo, dentro de um coletivo singular.

Verificou-se que a maioria dos pesares relatados nas rodas de TCI na comunidade quilombola estavam ligados a preocupação com doenças, principalmente inerentes ao 


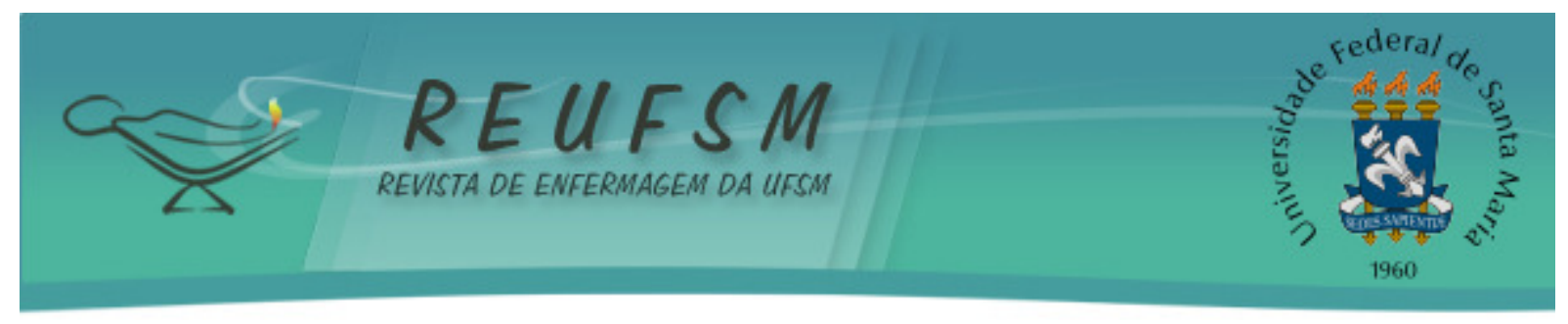

envelhecimento, o medo de tornar-se inútil diante dessas, bem como os conflitos familiares, que mostraram-se como eixos prejudiciais para a saúde mental dos integrantes.

Os participantes, ao compartilharem suas dores e dificuldades, tornaram-se atores importantes na busca de superações e soluções dos conflitos diários, propiciando a todos experimentarem suporte e apoio do grupo.

Como limitação deste estudo, destaca-se o fato de ter sido realizado nos encontros semanais do grupo de idosos, limitando algumas vezes o tempo para execução da roda de TCI.

Esta investigação buscou contribuir para a divulgação e implementação do uso de práticas inovadoras no campo psicossocial importante para desmistificar conceitos de uma estrutura social. Além disso, suscita implicações para novas pesquisas sobre a prática da TCI aliada à Atenção Primária em Saúde por meio da Estratégia Saúde da Família, para a produção do cuidar de enfermagem, na prevenção do adoecimento mental em contextos de vulnerabilidade social.

\section{AGRADECIMENTOS}

As rodas de TCI tiveram duração de um ano, correspondendo a vigência do plano de trabalho do projeto de extensão, com o apoio do Programa de Bolsas de Extensão, da PróReitoria de Extensão e Assuntos Comunitários da Universidade Federal da Paraíba.

\section{REFERÊNCIAS}

1. Paim J, Travassos C, Almeida C, Bahia L, Macinko J. O sistema de saúde brasileiro: história, avanços e desafios. Lancet. 2011;377(9779):1778-97.

2. Paulon S, Neves R, Dimenstein M, Nardi H, Bravo O, Galvão VABM, et al. A saúde mental no contexto da Estratégia Saúde da Família no Brasil. Psicol Am Lat. 2013;25:24-42.

3. Oliveira MAC, Pereira IC. Atributos essenciais da Atenção Primária e a Estratégia Saúde da Família. Rev Bras Enferm. 2013;66(N Esp):158-64.

4. Devera D, Costa-Rosa A. Marcos históricos da reforma psiquiátrica brasileira: Transformações na legislação, na ideologia e na práxis. Rev Psic UNESP. 2007;6(1):60-79.

5. Jorge MSB, Pinto DM, Quinderé PHD, Pinto AGA, Sousa FSP, Cavalcante CM. Promoção da Saúde Mental - Tecnologias do Cuidado: vínculo, acolhimento, co-responsabilização e autonomia. Ciênc Saúde Coletiva. 2011;16(7):3051-60.

6. Estanislau GM, Bressan RA. Saúde Mental na Escola: o que os educadores devem saber. Porto Alegre: Artmed; 2014. 


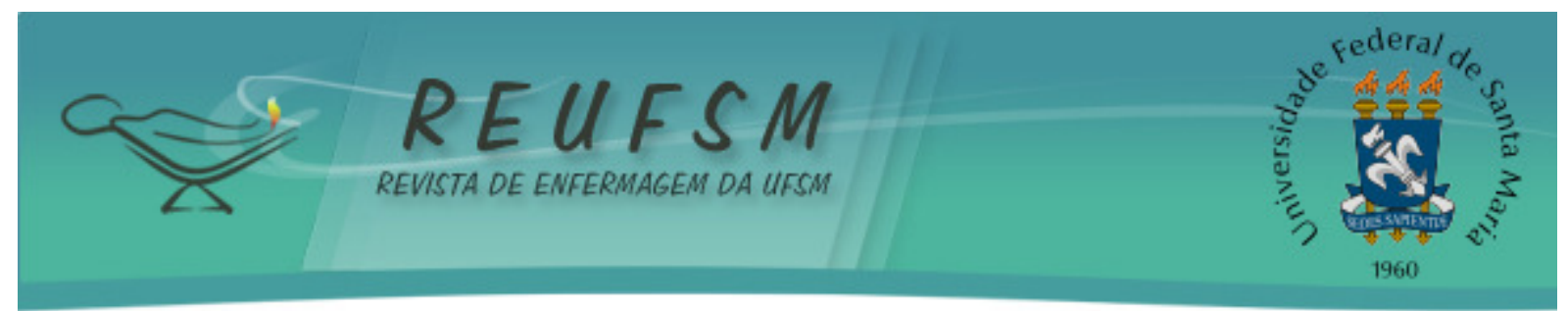

7. Ferreira Filha MO, Lazarte R, Dias MD. Terapia comunitária integrativa: uma construção coletiva do conhecimento. João Pessoa: Editora Universitária da UFPB; 2013. p.24-43.

8. Moura SG, Ferreira Filha MO, Moreira MASP, Simpson CA, Tura LFR, Silva AO. Representações sociais sobre terapia comunitária integrativa construídas por idosos. Rev Gaúcha Enferm [Internet]. 2017 [acesso em 2017 set 07];38(2):e55067. Disponível em: http://www.seer.ufrgs.br/RevistaGauchadeEnfermagem/article/view/55067.

9. Carvalho MAP, Dias MD, Miranda, FAN, Ferreira Filha, MO. Contribuições da terapia comunitária integrativa para usuários dos Centros de Atenção Psicossocial (CAPS): do isolamento à sociabilidade libertadora. Cad Saúde Pública [Internet]. 2013 [acesso em 2017 set 07];29(10):2028-38. Disponível em: http://www.scielo.br/pdf/csp/v29n10/a19v29n10.pdf.

10. Barreto AP. Terapia comunitária: passo a passo. $3^{\text {a }}$ ed. Fortaleza: LCR; 2008.

11. JataiI JM, Silva LMS. Enfermagem e a implantação da terapia comunitária integrativa na estratégia saúde da família: relato de experiência. Rev Bras Enferm Brasília [Internet]. 2012 [acesso em 2017 set 07];65(4):691-5. Disponível em: http://www.scielo.br/pdf/reben/v65n4/a21v65n4.pdf.

12. Camarotti MH, Melo DA, Souza SMC, Melo R, Bastos H. levantamento das informações advindas da formação da terapia comunitária integrativa realizadas pelo MISMECDF no período 2001 a 2010.Temas em Educação e Saúde [Internet]. 2012 [acesso em 2017 set 07];8:691-5. Disponível em: http://piwik.seer.fclar.unesp.br/tes/issue/view/604/showToc.

13. Brasil. Ministério da Saúde. Secretaria de Atenção à Saúde. Departamento de Atenção Básica. Política Nacional de Práticas Integrativas e Complementares no SUS - PNPIC-SUS. Brasília: Ministério da Saúde; 2006.

14. Brasil. Ministério da Saúde. Implementação da Lei 10.216 e a Política Nacional de Saúde Mental: cenário atual e perspectivas 2009 [Internet]. S/d [acesso em 2016 jul 15]. Disponível em:<http://portal.saude.gov.br/saude/area.cfm?id_area=925>.

15. Brasil. Ministério da Saúde. Núcleo Técnico da Política Nacional de Humanização. HumanizaSUS: Política Nacional de Humanização: a humanização como eixo norteador das práticas de atenção e gestão em todas as instâncias do SUS. Brasília: Ministério da Saúde; 2004. (Série B. Textos Básicos de Saúde).

16. Brasil. Ministério da Saúde. Portaria $\mathrm{n}^{\circ}$ 2.488, de outubro de 2011. Aprova a Política Nacional de Atenção Básica, estabelecendo a revisão de diretrizes e normas para a organização da Atenção Básica, para a Estratégia Saúde da Família (ESF) e o Programa de Agentes Comunitários de Saúde (PACS). Brasília; 2011.

17. Barreto A. Terapia comunitária passo a passo. Fortaleza: Gráfica LCR; 2005.

18. Camarotti MH, Gomes DO. Terapia Comunitária nas relações sociais. In: Osorio LC, Valle MEP. Manual de Terapia Familiar. Porto Alegre: Artmed; 2009.

19. Jatai JM, Silva LMS. Enfermagem e a implantação da Terapia Comunitária Integrativa na Estratégia Saúde da Família: relato de experiência. Rev Bras Enferm. 2012;65(4):691-5.

20. Lima GD, Gianasi LM. Etnoterritorialidade Quilombola de Macuco no município de Minas Novas e Chapada do Norte/Vale do Jequitinhonha-Minas Gerais, Brasil: mapeamentos e análises. Rev Ateliê Geográfico. 2011;5(1):37-63. 


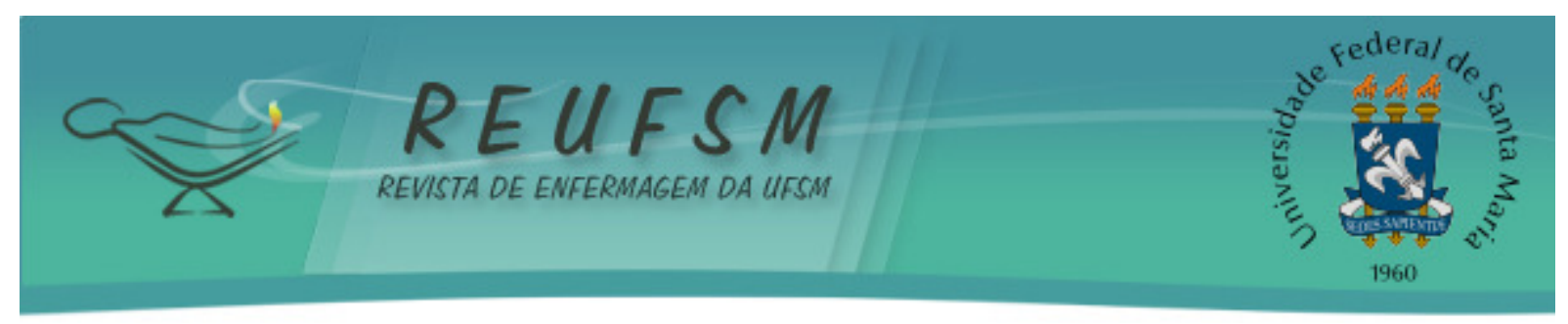

21. Fundação Palmares. Comunidades Quilombolas [Internet]. Brasília; 2014 [acesso em 2014 jun 13]. Disponível em: http://www.palmares.gov.br/?page_id=88.

22. Ferreira Filha MO, Dias MD, Andrade FB, Lima EAR, Ribeiro FF, Silva MSS. A terapia comunitária como estratégia de promoção à saúde mental: o caminho para o empoderamento. Rev Eletrônica Enferm [Internet]. 2009 [acesso em 2014 jun 13];11(4):964-70. Disponível em: https://www.fen.ufg.br/fen_revista/v11/n4/pdf/v11n4a22.pdf.

23. Kantorski LP, Coimbra VCC, Demarco DA, Eslabão AD, Nunes CK, Guedes AC. A importância das atividades de suporte terapêutico para o cuidado em um Centro de Atenção. J Nurs Health. 2011;1(1):4-13.

24. Andrade FB, Ferreira Filha MO, Dias MD, Silva AO, Costa ICC, Lima EAR, et al. Promoção da saúde mental do idoso na atenção básica: as contribuições da terapia comunitária. Texto \& Contexto Enferm. 2010;19(1):129-36.

25. Carvalho MAP, Romero ROG, Ferreira Filha MO. Terapia comunitária no centro de apoio psicossocial: concepções dos acadêmicos de enfermagem. Rev Enferm UFPE. 2013;7(5):4389-94.

Data de submissão: 03/10/2015

Data de aceite: 23/04/2017

Autor correspondente: Sanni Moraes de Oliveira

Endereço: Rua Bancário Lourenço Vieira de Souza, Bancários, João Pessoa, Paraíba, Brasil CEP: 58051-570

Email: sannidsm@gmail.com 